\title{
Articles
}

\section{Two hour plasma glucose is not unequivocally predictive for early death in men with impaired fasting glucose: more results from the Paris Prospective Study}

\author{
B. Balkau, A. Forhan, E. Eschwège \\ INSERM U258-IFR69 and Faculty of Medicine University Paris XI, Villejuif, France
}

\section{Abstract}

Aims/hypothesis. We examined whether the 2-h plasma glucose (2hPG) concentration after a $75 \mathrm{~g}$ OGTT is predictive of death in men with a diabetic, an impaired or a normal fasting plasma glucose concentration (DM-FPG: $\geq 7.0 \mathrm{mmol} / \mathrm{l}$; IFG: 6.1-6.9 mmol/l; normal-FPG: $<6.1 \mathrm{mmol} / \mathrm{l})$.

Methods. The 17-year mortality of 7018 men, aged 44 to 55 years, from the Paris Prospective Study, who were not known to be diabetic at baseline was studied. Results. The $2 \mathrm{hPG}$ was not associated with early mortality in men with a DM-FPG in contrast to men with an IFG or a normal-FPG; for an increase from 10 to $11 \mathrm{mmol} / \mathrm{l}$ in the $2 \mathrm{hPG}$, the age-adjusted hazards ratios were 1.01 (95\% CI 0.95-1.08), 1.15 (1.03-1.28) and $1.24(1.18-1.31)$ respectively. Coronary heart dis- ease mortality and within this category sudden death but not ischaemic heart disease death, were related with $2 \mathrm{hPG}$ but only in the men with normal FPG. However, the prediction by $2 \mathrm{hPG}$ did not differ between the men with DM-FPG, an IFG or a normalFPG: the overall age-adjusted hazards ratios for these three causes of death were 1.09 (1.00-1.18), 1.13 (1.02-1.26) and 1.13 (0.99-1.29), respectively.

Conclusion/interpretation. $2 \mathrm{hPG}$ is unequivocally prognostic for all-cause mortality only in men with normal FPG. Screening men with an IFG by using a $75 \mathrm{~g}$ OGTT is of limited benefit. [Diabetologia (2002) 45:1224-1230]

Keywords Diabetes, epidemiology, hyperglycaemia, mortality, coronary heart disease.
Previous studies have shown that the 2-h plasma glucose $(2 \mathrm{hPG})$ concentration after a $75 \mathrm{~g}$ oral glucose load (OGTT) is predictive of all cause, cardiovascular, and coronary mortality $[1,2,3,4,5]$. Some studies have used arbitrary classifications for the $2 \mathrm{hPG}$, oth-

Received: 28 February 2002 / Revised: 24 April 2002

Published online: 6 July 2002

C) Springer-Verlag 2002

Corresponding author: Dr. B. Balkau, INSERM U258-IFR69, 16 Avenue Paul Vaillant-Couturier, 94807 Villejuif, France, E-mail: balkau@vjf.inserm.fr

Abbreviations: FPG, Fasting plasma glucose; 2hPG, 2-hour plasma glucose; DM-FPG, diabetic, fasting plasma glucose $\geq 7.0 \mathrm{mmol} / \mathrm{l}$; normal-FPG, normal, fasting plasma glucose

< $6.1 \mathrm{mmol} / \mathrm{l}$; DM-2hPG, diabetic 2-h plasma glucose $\geq 11.1 \mathrm{mmol} / \mathrm{l}$; normal-2hPG, normal 2-h plasma glucose $<7.8 \mathrm{mmol} / \mathrm{l}$ ers have used those defined by the American Diabetes Association (ADA) and the World Health Organisation (WHO): diabetes (DM-2hPG: $\geq 11.1 \mathrm{mmol} / \mathrm{l})$, impaired glucose tolerance (IGT: $7.8-11.0 \mathrm{mmol} / \mathrm{l}$ ), normal (normal-2hPG: $<7.8 \mathrm{mmol} / \mathrm{l}$ ) [6, 7]. When the $2 \mathrm{hPG}$ concentration was analysed as a continuous variable for the men in the Paris Prospective Study, it predicted death by all causes and by coronary heart disease [8].

The WHO and the European Diabetes Policy Group recommend that all subjects with an IFG should be given an OGTT [7,9]. The question remains, as to whether the $2 \mathrm{hPG}$ carries a risk for certain causes of early death for all three groups of subjects: diabetic by fasting plasma glucose (DM-FG: $\geq 7.0 \mathrm{mmol} / \mathrm{l}$ ), impaired fasting plasma glucose (IFG: 6.1-6.9 mmol/1), normal fasting plasma glucose (normal-FPG: <6.1 mmol/l). 
We studied the effect of the $2 \mathrm{hPG}$ concentration on death by all causes, by cardiovascular diseases and by cancer. These were the principal causes of death in the Paris Prospective Study cohort in the men categorized according to their fasting plasma glucose concentration: DM-FPG, IFG, normal-FPG.

\section{Subjects and methods}

Study cohort. 7018 Paris policeman, aged 44 to 55 years and who were not known to have diabetes before the baseline examination were followed-up for 17 years for causes of death.

All men completed a 2-h, $75 \mathrm{~g}$ OGTT and plasma glucose and insulin concentrations were measured on both the fasting and 2-h samples and cholesterol concentrations on the fasting sample. The men were questioned about smoking habits and their blood pressure, BMI and iliac circumference were measured. The Paris Prospective Study participants were examined during a periodic yearly health examination required for Paris policemen by their employer. The investigations were carried out in accordance with the principles of the 1964 Helsinki declaration.

The dates of death were obtained from official sources and information on the causes of death from the treating physician, hospital records and the family of the deceased. The International Classification of Diseases (ICD), revisions 8 and 9 [10], was used to code the causes of death: coronary heart disease were: 410 to 414 (ischaemic heart disease), 427.0 (congestive heart failure), 427.1 (left ventricular failure), 519.1 (acute oedema of lung), 782 (symptoms referable to cardiovascular and lymphatic system), 795.0 (sudden death); cardiovascular disease: coronary heart disease and 390-459; cancers: 140 to 239.

Statistical analyses. Characteristics of the three groups of men: DM-FPG, IFG, normal-FPG were compared using chi-squared or Student's $t$ tests (with glucose and insulin concentrations log transformed). The observed relative risks shown in the figure used the number of person-years of follow-up as the denomi- nator for each $2 \mathrm{hPG}$ class and the reference interval was centred on $6.0 \mathrm{mmol} / \mathrm{l}$. The Cox proportional hazards model was used to assess the effect of the $2 \mathrm{hPG}$ concentration (transformed logarithmically to ensure a more symmetric distribution) on time until death, after adjusting for age. Both linear and quadratic glucose terms were used in the models as the relations were not always linear; the $p$ values in Fig. 1 were derived from a chi-square test to compare nested models (model 1: age; model 2: age, linear and quadratic terms in $2 \mathrm{hPG}$ ); the hazards ratios were modelled by the continuous lines in the Figure. The age-adjusted effect of $2 \mathrm{hPG}$ was compared between the three FPG groups by chi-square tests of nested models and when there was a significant difference, the same method was used for the pair-wise comparison of FPG groups. Hazards ratios (95\% CI) were calculated for an increase in $2 \mathrm{hPG}$ concentrations from 10 to $11 \mathrm{mmol} / \mathrm{l}$ after adjusting for age alone and after further adjustments were made for other risk factors: systolic blood pressure, cholesterol concentration, iliac circumference, current smoking, fasting and 2-h insulin concentrations. An overall hazards ratio was calculated if the previous test indicated that the $2 \mathrm{hPG}$ did not have a different effect in the three FPG groups; adjustment was made for the FPG group. To provide more easily interpretable hazards ratios, the all-cause mortality hazard ratios were also calculated for the nine groups: DM-2hPG, IGT, normal-2hPG by DMFPG, IFG, normal-FPG. A $p$ value of less than 0.05 was considered to be statistically significant.

\section{Results}

In this cohort of middle aged men, $3.4 \%$ had a DMFPG and $17.1 \%$ an IFG (Table 1). As expected the glucose and insulin concentrations differed significantly between the three groups: normal-FPG, IFG, DM-FPG $(p<0.0001)$; BMI, centrally obesity as measured by the iliac circumference, cholesterol concentration and systolic blood pressure also differed $(p<0.05)$.

Table 1 Baseline characteristics of the 7018 men according to their fasting plasma glucose: diabetic, impaired fasting glucose, normal (DM-FPG, IFG, normal-FPG: $\geq 7.0,6.1-6.9$ and <6.1 mmol/1). The Paris Prospective Study

\begin{tabular}{|c|c|c|c|c|c|}
\hline & \multicolumn{5}{|c|}{ Fasting plasma glucose (mmol/l) } \\
\hline & $\begin{array}{l}<6.0 \\
\text { (normal-FPG) }\end{array}$ & & $\begin{array}{l}6.0-6.9 \\
(\mathrm{IFG})\end{array}$ & & $\begin{array}{l}\geq 7.0 \\
(\mathrm{DM}-\mathrm{FPG})\end{array}$ \\
\hline Characteristic & $(n=5575)$ & $p^{\mathrm{a}}$ & $(n=1203)$ & $p^{\mathrm{a}}$ & $(n=240)$ \\
\hline Age (years) & $48.9(2.0)$ & 0.11 & $49.0(1.8)$ & 0.08 & $49.6(1.8)$ \\
\hline $\mathrm{BMI}\left(\mathrm{kg} / \mathrm{m}^{2}\right)$ & $25.6(3.1)$ & 0.0001 & $27.2(3.2)$ & 0.0001 & $28.7(3.8)$ \\
\hline 2-hour plasma glucose $(\mathrm{mmol} / \mathrm{l})$ & $5.4(1.6)$ & 0.0001 & $6.5(1.9)$ & 0.0001 & $10.1(3.7)$ \\
\hline Fasting insulin (mU/l) & $11.2(8.1)$ & 0.0001 & $15.3(13.5)$ & 0.0001 & $21.9(14.2)$ \\
\hline 2-hour insulin (mU/l) & $40.3(35.4)$ & 0.0001 & $60.9(55.6)$ & 0.0002 & $68.9(50.9)$ \\
\hline Cholesterol $(\mathrm{mmol} / \mathrm{l})$ & $5.6(1.1)$ & 0.0001 & $5.8(1.2)$ & 0.05 & $6.0(1.1)$ \\
\hline Systolic blood pressure (mmHg) & $141(20)$ & 0.0001 & $152(23)$ & 0.0001 & $163(29)$ \\
\hline Smoking & $59 \%$ & 0.0003 & $53 \%$ & 0.23 & $57 \%$ \\
\hline
\end{tabular}

Data are means (SD) or \%

${ }^{a} p$ Comparing the adjacent groups 
Table 2 Causes of death according to fasting plasma glucose groups: diabetic, impaired fasting glucose, normal (DM-FPG, IFG, normal-FPG: $\geq 7.0,6.1-6.9,<6.1 \mathrm{mmol} / \mathrm{l})$ after 17 years of follow-up and the $p$-values for tests of significance comparing the effects of the 2-h plasma glucose in these fasting glucose groups. The Paris Prospective Study
Deaths $\%(n)$ age-adjusted $p$ values for tests of statistical significance of the 2-h plasma glucose

In each FPG Overall difference $\quad$ The differences between specific
class between FPG groups

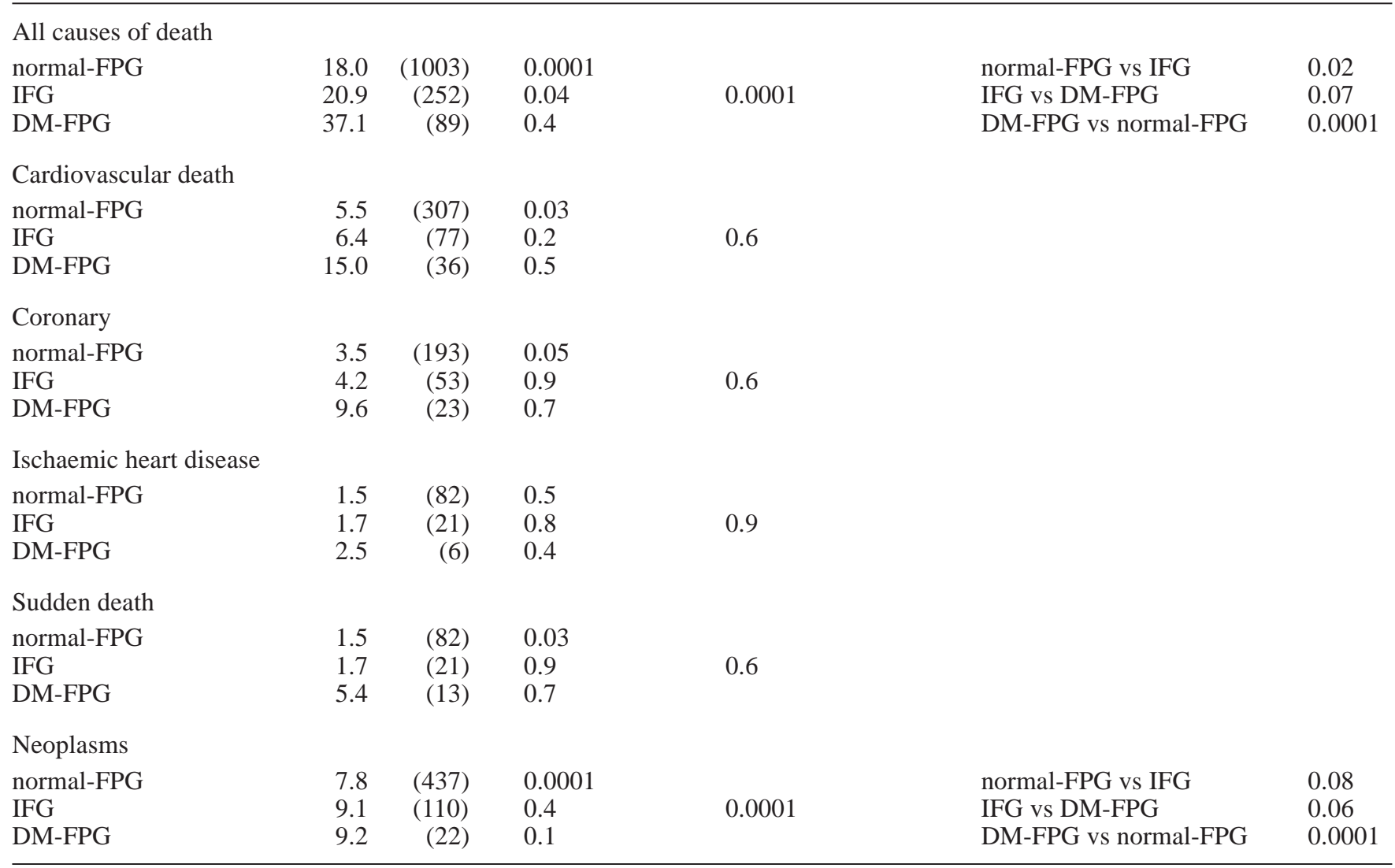

After 17 years of follow-up, 1344 men had died, $37 \%$ of those with a DM-FPG, $21 \%$ with IFG and $18 \%$ with a normal-FPG (Table 2), thus there was little difference in the risk of mortality between the men with IFG and men with normal-FPG.

The $2 \mathrm{hPG}$ (analysed as a continuous variable) was not predictive of all-cause mortality for the DM-FPG men $(p=0.4)$ (Fig. 1, Table 2); in contrast, there were significant relations $(p<0.04, \mathrm{p}<0.0001$ respectively) for the IFG and normal-FPG men. A difference was found between the effect of $2 \mathrm{hPG}$ concentrations in these three FPG groups $(p<0.0001)$ (Table 2), in particular between the men with normal-FPG and those with IFG or DM-FPG $(p<0.02, p<0.0001)$. For example, an increase in $2 \mathrm{hPG}$ concentration from 10 to $11 \mathrm{mmol} / \mathrm{l}$ was associated with hazards ratios for DM-FPG: 1.01 (95\% CI: 0.95-1.08), IFG: 1.15 (1.03-1.28) and normal-FPG: 1.24 (1.18-1.31) (Table 3 ).

Further, the $2 \mathrm{hPG}$ concentration was analysed quantitatively in the three categories: DM-2hPG, IGT and normal-2hPG, rather than as a continuous variable. In the DM-FPG men, the $2 \mathrm{hPG}$ class had no effect on the hazards ratios for all causes of death $(p=0.7)$ and there was no trend $(p=0.4)$ (Table 4); for the men with IFG this less powerful grouped analysis gave non-significant results $(p=0.3$ for difference, $p=0.1$ for trend). For the normal-FPG men the hazards ratios were different between the three 2-h categories $(p<0.0001)$ : compared with men with a normal-2hPG, there was a fourfold mortality increase for the DM-2hPG men, a doubling for the IGT men. However, the DM-2hPG men were only a very small fraction $(0.6 \%)$ of this cohort.

For the 240 men with DM-FPG, $15.0 \%$ died of cardiovascular causes compared with $6.4 \%$ of the 1203 men with IFG and $5.5 \%$ of the 5575 men with normalFPG (Table 2 ). Again there was no relation with $2 \mathrm{hPG}$ in men with DM-FPG $(p=0.5)$ nor in men with IFG $(p=0.2)$; however, there was a curvilinear relation for men with normal-FPG $(p<0.03)$. There was no difference however, in the relation between the $2 \mathrm{hPG}$ 
Fig. 1A-D. Distribution of the 2-h plasma glucose in men with a normal-FPG $(n=5575)$, an IFG $(n=1203)$ or a DM-FPG $(n=240)$, the observed relative risks for death (with reference to $6.0 \mathrm{mmol} / \mathrm{l})(\mathbf{)})$, and the modelled hazards ratios after adjustment for age (-). The $p$ values indicate whether the 2-h glucose was predictive of mortality. The Paris Prospective Study. A All causes of death, B coronary deaths, $\mathbf{C}$ sudden death, $\mathbf{D}$ fatal cancers
A
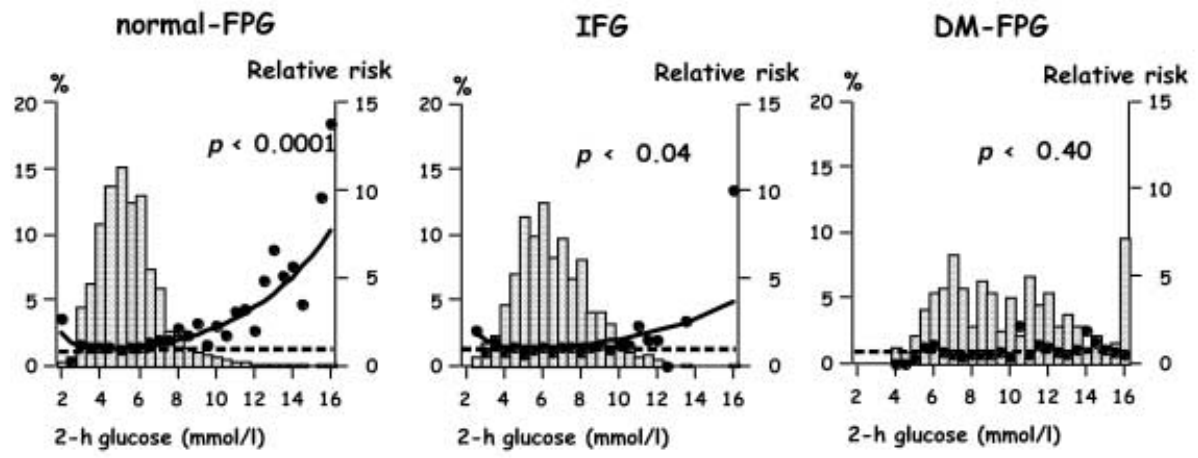

B
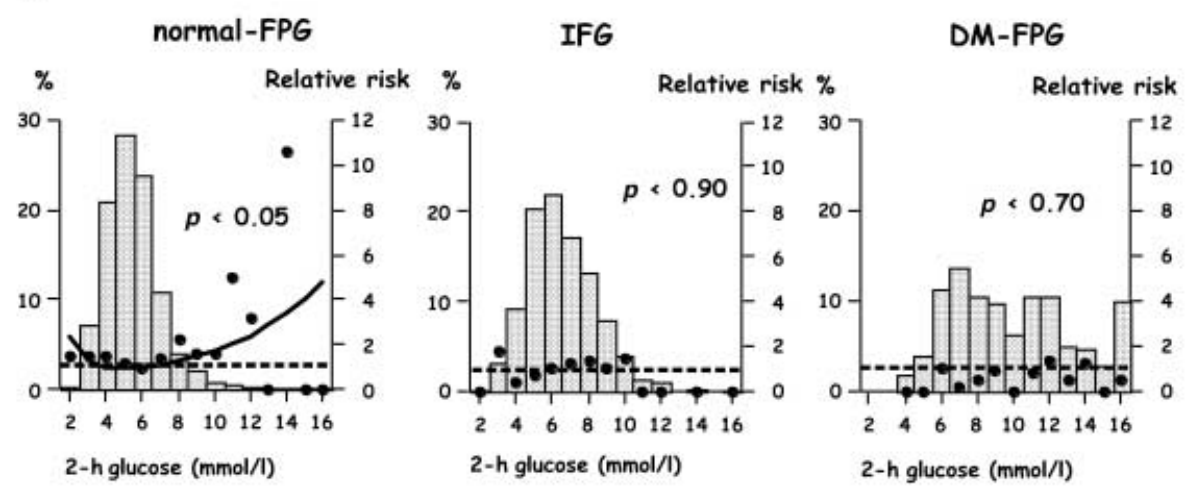

C
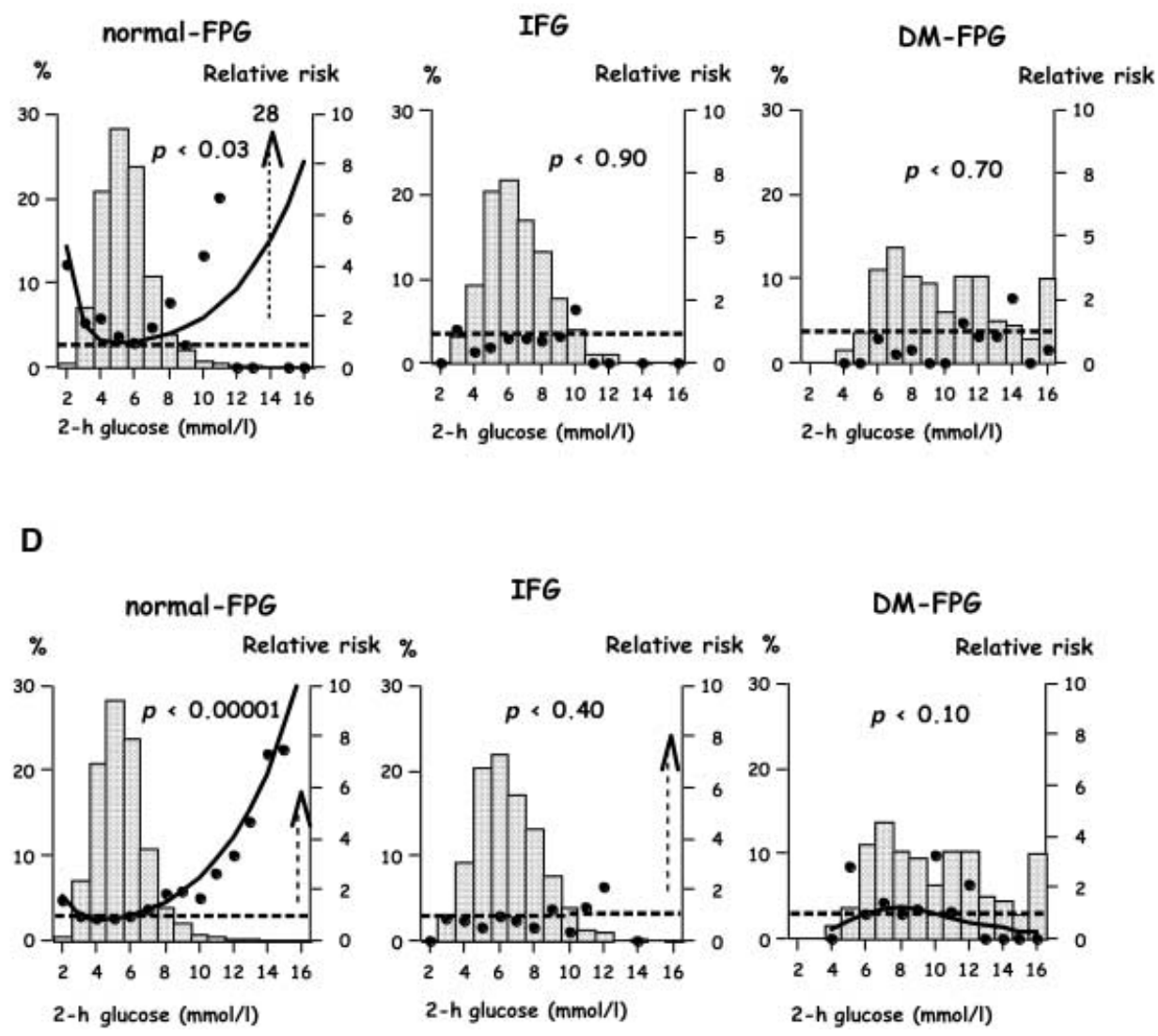
Table 3 Hazards ratios (95\% CI) for death by various causes, for an increase in 2-h plasma glucose from 10.0 to $11.0 \mathrm{mmol} / \mathrm{l}$ for men according to their fasting glucose: diabetic, impaired fasting glucose or normal (DM-FPG, IFG and normal-FPG: $\geq 7.0,6.1-6.9$ and $<6.1 \mathrm{mmol} / \mathrm{l})$ after 17 years of follow-up. If there was no significant difference for $2 \mathrm{hPG}$ between the FPG groups, an overall hazards ratio is also shown. The Paris Prospective Study

Hazards ratios adjusted for

\begin{tabular}{lll}
\hline Age & $\begin{array}{l}\text { Age, smoking, iliac circumference } \\
\text { systolic blood pressure, cholesterol }\end{array}$ & $\begin{array}{l}\text { Previous column plus fasting } \\
\text { and 2-h insulin }\end{array}$
\end{tabular}

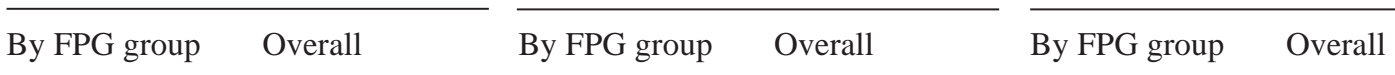

All causes of death

$\begin{array}{ll}\text { normal-FPG } & 1.24(1.18-1.31) \\ \text { IFG } & 1.15(1.03-1.28) \\ \text { DM-FPG } & 1.01(0.95-1.08)\end{array}$

$\begin{array}{ll}1.18(1.11-1.24) & 1.20(1.13-1.26) \\ 1.12(1.01-1.25) & 1.10(0.98-1.23) \\ 0.99(0.93-1.06) & 0.99(0.92-1.06)\end{array}$

Cardiovascular death

\begin{tabular}{|c|c|c|c|c|c|c|}
\hline normal-FPG & $1.14(1.03-1.27)$ & \multirow[b]{2}{*}{$1.09(1.02-1.16)$} & $1.07(0.96-1.20)$ & \multirow[b]{2}{*}{$1.05(0.98-1.13)$} & $1.08(0.96-1.20)$ & \multirow[b]{2}{*}{$1.04(0.97-1.12)$} \\
\hline IFG & $1.15(0.95-1.39)$ & & $1.11(0.91-1.35)$ & & $1.05(0.85-1.30)$ & \\
\hline \multicolumn{7}{|l|}{ Coronary } \\
\hline normal-FPG & $1.18(1.04-1.34)$ & \multirow{3}{*}{$1.09(1.00-1.18)$} & $1.11(0.98-1.26)$ & \multirow{3}{*}{$1.06(0.97-1.15)$} & $1.12(0.99-1.28)$ & \multirow{3}{*}{$1.05(0.96-1.14)$} \\
\hline IFG & $1.04(0.80-1.35)$ & & $1.00(0.77-1.31)$ & & $0.92(0.68-1.24)$ & \\
\hline DM-FPG & $1.04(0.92-1.17)$ & & $1.02(0.90-1.15)$ & & $1.00(0.88-1.14)$ & \\
\hline normal-FPG & $1.14(0.92-1.40)$ & \multirow{3}{*}{$1.13(0.99-1.29)$} & $1.04(0.84-1.29)$ & \multirow{3}{*}{$1.09(0.95-1.25)$} & $1.04(0.84-1.30)$ & \multirow{3}{*}{$1.07(0.92-1.23)$} \\
\hline IFG & $1.13(0.78-1.63)$ & & $1.12(0.77-1.63)$ & & $0.95(0.58-1.54)$ & \\
\hline DM-FPG & $1.13(0.92-1.38)$ & & $1.13(0.91-1.40)$ & & $1.10(0.87-1.38)$ & \\
\hline \multicolumn{7}{|l|}{ Sudden death } \\
\hline normal-FPG & $1.25(1.07-1.47)$ & $1.13(1.02-1.26)$ & $1.21(1.03-1.42)$ & $1.10(0.99-1.23)$ & $1.24(1.05-1.46)$ & $1.09(0.97-1.22)$ \\
\hline normal-FPG & $1.28(1.19-1.38)$ & & $1.23(1.14-1.32)$ & & $1.26(1.16-1.36)$ & \\
\hline IFG & $1.12(0.95-1.32)$ & & $1.09(0.92-1.29)$ & & $1.12(0.95-1.32)$ & \\
\hline DM-FPG & $0.84(0.68-1.03)$ & & $0.81(0.65-1.00)$ & & $0.79(0.63-0.99)$ & \\
\hline
\end{tabular}

and cardiovascular mortality between these three FPG groups and the common hazards for an increase from 10 to $11 \mathrm{mmol} / \mathrm{l}$ was 1.09 (1.02-1.16) (Table 3).

The risks associated with $2 \mathrm{hPG}$ for cardiovascular and coronary death and its major components, ischaemic heart disease and sudden death were similar. As there were no differences between these relations according to the three FPG groups (Fig. 1, Table 2), the common hazards ratios associated with a $1 \mathrm{mmol} / \mathrm{l}$ increase in $2 \mathrm{hPG}$ from $10 \mathrm{mmol} / \mathrm{l}$ were 1.09 (1.00-1.18) for coronary death, $1.13(0.99-1.29)$ for ischaemic heart disease death and $1.13(1.02-1.26)$ for sudden death (Table 3 ).

The major cause of death in this cohort was neoplasms, which were overall $35 \%$ more frequent than cardiovascular deaths, with similar frequencies in men with a DM-FPG, IFG, normal-FPG of $9.2 \%, 9.1 \%$ and $7.8 \%$, respectively (Table 2 ). In the men with DMFGP there was a trend for a negative relation $(p<0.1)$ and in the men with normal-FPG a positive relation $(p<0.0001)$ (Fig. 1). A difference was found in the effect of the $2 \mathrm{hPG}$ between these three FPG groups $(p<0.0001)$ and in particular between the DM-FPG and the normal-FPG men $(p<0.0001)$ (Table 2). For example for a $1 \mathrm{mmol} / \mathrm{l}$ increase in the $2 \mathrm{hPG}$ concentration from $10 \mathrm{mmol} / \mathrm{l}$ for the men with DM-FPG the age-adjusted hazards ratio was $0.84(0.68-1.03)$ and in the IFG men $1.12(0.95-1.32)$ but in the normal-FPG men, the relation was positive with a hazards ratio of 1.28 (1.19-1.38) (Table 3).

After further adjusting for other factors, the hazards ratios for a $1 \mathrm{mmol} / \mathrm{l}$ increase in $2 \mathrm{hPG}$ from $10 \mathrm{mmol} / \mathrm{l}$ were attenuated. For all causes of death, in IFG men the relation with $2 \mathrm{hPG}$ was no longer statistically significant. For cardiovascular disease and its components the relations were no longer significant. For neoplasms, the most frequent cause of death, the relation was still statistically significant and positive for 
Table 4 Age-adjusted hazards ratios $(95 \% \mathrm{CI})$ for death by all causes and numbers of men at baseline according to their fasting plasma glucose concentration: diabetic, impaired fasting glucose, normal (DM-FPG, IFG, normal-FPG: $\geq 7.0,6.1-6.9$, $<6.1 \mathrm{mmol} / \mathrm{l}$ ) and their 2-h plasma glucose concentration: dia- betic, impaired glucose tolerant, normal (DM-2hPG, IGT, normal-2hPG: $\geq 11.1,7.8-11.1,<7.8 \mathrm{mmol} / \mathrm{l})$ after 17 years of follow-up. $p$ values test the differences between and the trends across 2 hPG groups, for each of the three FPG groups. The Paris Prospective Study

\begin{tabular}{|c|c|c|c|c|c|c|}
\hline & & \multicolumn{3}{|c|}{ 2-h plasma glucose $\mathrm{mmol} / \mathrm{l}$} & \multicolumn{2}{|l|}{$p$ values } \\
\hline & & $<7.8$ & $7.8-11.1$ & $\geq 11.1$ & Difference & Trend \\
\hline \multirow[t]{3}{*}{ Fasting plasma glucose $(\mathrm{mmol} / \mathrm{l})$} & $<6.1$ & $\begin{array}{l}1 \\
n=5204\end{array}$ & $\begin{array}{l}1.92(1.56-2.37) \\
n=326\end{array}$ & $\begin{array}{l}4.29(2.90-6.33) \\
n=45\end{array}$ & 0.0001 & 0.0001 \\
\hline & $6.1-7.0$ & $\begin{array}{l}1.20(1.02-1.40) \\
n=927\end{array}$ & $\begin{array}{l}1.42(1.09-1.85) \\
n=253\end{array}$ & $\begin{array}{l}2.07(0.99-4.36) \\
n=23\end{array}$ & 0.3 & 0.1 \\
\hline & $\geq 7.0$ & $\begin{array}{l}2.18(1.51-3.15) \\
n=82\end{array}$ & $\begin{array}{l}2.21(1.46-3.35) \\
n=66\end{array}$ & $\begin{array}{l}2.56(1.84-3.55) \\
n=92\end{array}$ & 0.7 & 0.4 \\
\hline
\end{tabular}

normal-FPG men, but for the men with DM-FPG the $2 \mathrm{hPG}$ became protective after adjustment (Table 3 ).

\section{Discussion}

For the 240 men with a DM-FPG, $2 \mathrm{hPG}$ is not predictive of all-cause mortality; this is not due to lack of power of this study as the hazards ratio for a $1 \mathrm{mmol} / \mathrm{l}$ change is low and the relation with $2 \mathrm{hPG}$ differs from those of normal-FPG and IFG men. Over the 17 years of this study, these DM-FPG men would have metabolic disturbances along with hyperglycaemia which would contribute to their risk of early death and perhaps overshadow the effect of baseline $2 \mathrm{hPG}$ concentrations. For neoplasms, mortality shows a trend of decreasing with $2 \mathrm{hPG}$, with an age-adjusted hazards ratio of $0.84(0.68-1.03)$ when the $2 \mathrm{hPG}$ increases from 10 to $11 \mathrm{mmol} / \mathrm{l}$. Again this relation is different to that of the normal-FPG men. For the cardiovascular causes of death studied, the effects of $2 \mathrm{hPG}$ are not different from that in the men with IFG or normal-FPG.

For the men in this cohort with IFG, $2 \mathrm{hPG}$ is predictive of all causes death, with an age-adjusted $15 \%$ increase in risk when the glucose concentration changes from 10 to $11 \mathrm{mmol} / \mathrm{l}$; this increase is reduced to $10 \%$ after further adjustment. The major causes of death are neoplasms (44\%) followed by cardiovascular disease $(31 \%)$. Although the increases in risk for this $1 \mathrm{mmol} / \mathrm{l}$ change in glucose concentration are $12 \%$ and $15 \%$ respectively; they are not different from zero. Screening the 1203 men with IFG by an OGTT, (i.e. $17 \%$ of our cohort) would yield 23 men who are diabetic on the $2 \mathrm{hPG}$ criterion $(0.3 \%$ of our cohort) and 253 men with IGT (3.6\% of our cohort); the all-cause mortality hazards ratios did not differ between the groups DM-2hPG, IGT and normal-2hPG. Equally the risk of death by cardiovascular disease did not differ between these groups. Thus the recommendation of the WHO and the European Diabetes Policy Group to screen IFG men with an
OGTT does not seem to be warranted on the basis of early mortality $[7,9]$.

For the $79 \%$ of men who have a normal-FPG, $2 \mathrm{hPG}$ is predictive of all causes of death and notably of sudden death and cancers; an increase in $2 \mathrm{hPG}$ from 10 to $11 \mathrm{mmol} / \mathrm{l}$, is associated with close to a $25 \%$ increase for all-cause deaths, for sudden death and for fatal cancers. We have already noted the high cancer mortality in the men with both DM-FPG and DM-2hPG [11]. These relations are strong and would remain significant even after correction for multiple testing.

For the men with DM-FPG in the DECODE study [3], which includes the Paris Prospective Study, there is approximately a $30 \%$ increase in mortality risk for men with a DM-2hPG compared with the normal$2 \mathrm{hPG}$ men; for the men with IFG, the corresponding increase in risk is $100 \%$. In the Paris Prospective Study these risks are lower $(20 \%$ and $70 \%$ respectively) for the men with DM-FPG and IFG. Therefore a similar analysis in the DECODE study could show a higher relative risk associated with the continuous $2 \mathrm{hPG}$ concentration for these two groups of men.

In the Mauritian, Fijian, Nauruan study of mortality [12] the all-cause mortality in men with DM-FPG, carries similar hazards ratios in those with and without a DM-2hPG; however, in agreement with our results, in men without a DM-FPG there is a difference in risk between those with and without a DM-2hPG. These same relations hold for death by cardiovascular disease, agreeing with our study. Cancer mortality rates are also quoted in this report [12]; this cause of death is five times less frequent than cardiovascular causes, probably because the cohorts are only followed up until an average age of 50 years and there are too few cancer deaths.

The relation between sudden death and diabetes has been reported in the Paris Prospective Study [13,14]. In comparison with men who are normal on both FPG and $2 \mathrm{hPG}$ criteria, the risk of sudden death is more than three times higher for men with a normal FPG 
and a DM-2hPG, and for men with DM-FPG, whatever their $2 \mathrm{hPG}$ concentration.

Some of the men without a DM-FPG but with a high $2 \mathrm{hPG}$ could be screened because they have high $\mathrm{HbA}_{1 \mathrm{c}}$. A recent article shows that for the 101 subjects with a DM-2hPG, $45 \%$ have a DM-FPG whereas $62 \%$ have an $\mathrm{HbA}_{1 \mathrm{c}}$ above $6.1 \%$ (mean $\pm 2 \mathrm{SD}$ ), enabling the detection of additional subjects with a DM-2hPG [15]. As commented by the American Diabetes Association Expert Committee [6], the FPG is strongly recommended in clinical settings because it is easier to carry out than an OGTT and less expensive. It is more convenient and acceptable to patients and more reproducible.

Knowledge of the $2 \mathrm{hPG}$ concentration could benefit men with a normal-FPG to be targetted for preventive action for sudden death and perhaps for cancers. For men with IFG, the mortality risk associated with $2 \mathrm{hPG}$ is much lower, and the limited benefit from only screening these subjects with an OGTT is not likely to be worthwhile.

\section{References}

1. Balkau B, Shipley M, Jarrett RJ et al. (1998) High blood glucose concentration is a risk factor for mortality in middle-aged nondiabetic men. 20-year follow-up in the Whitehall Study, the Paris Prospective Study, and the Helsinki Policemen Study. Diabetes Care 21: 360-367

2. Coutinho M, Gerstein HC, Wang Y, Yusuf S (1999) The relationship between glucose and incident cardiovascular events. A metaregression analysis of published data from 20 studies of 95,783 individuals followed for 12.4 years. Diabetes Care 22: 233-420

3. The DECODE Study Group on behalf of the European Diabetes Epidemiology Group (1999) Glucose tolerance and mortality: comparison of WHO and American Diabetes Association diagnostic criteria. The DECODE study group. European Diabetes Epidemiology Group. Diabetes Epidemiology: collaborative analysis of diagnostic criteria in Europe. Lancet 354: 617-621
4. Vegt F de, Dekker JM, Ruhe HG et al. (1999) Hyperglycaemia is associated with all-cause and cardiovascular mortality in the Hoorn population: the Hoorn Study. Diabetologia 42: 926-931

5. The DECODE Study Group on behalf of the European Diabetes Epidemiology Group (2001) Glucose tolerance and cardiovascular mortality:comparison of fasting and 2-hour diagnostic criteria. Arch Intern Med 161: 397-405

6. The expert committee on the diagnosis and classification of diabetes mellitus (1997) Report of the expert committee on the diagnosis and classification of diabetes mellitus. Diabetes Care 20: 1183-1197

7. World Health Organisation Consultation (1999) Definition, diagnosis and classification of diabetes mellitus and its complications. Part 1: Diagnosis and classification of diabetes mellitus. Report of a WHO Consultation 99.2. Geneva, Switzerland

8. Balkau B, Bertrais S, Ducimetiere P, Eschwege E (1999) Is there a glycemic threshold for mortality risk? Diabetes Care 22: 696-699

9. European Diabetes Policy Group (1999) A desktop guide to Type 2 diabetes mellitus. Diabet Med 16: 716-773

10. International Classification of Diseases, Injuries and Causes of Death. Revision 9 (1997) Geneva, World Health Organisation

11. Eschwege E, Charles MA, Simon D, Thibult N, Balkau B (2001) From policemen to policies: what is the future for 2-h glucose? The Kelly West Lecture 2000. Diabetes Care 24: 1945-1950

12. Shaw JE, Hodge AM, Courten $M$ de, Chitson $P$, Zimmet PZ (1999) Isolated post-challenge hyperglycaemia confirmed as a risk factor for mortality. Diabetologia 42 : 1050-1054

13. Jouven X, Desnos M, Guerot C, Ducimetiere P (1999) Predicting sudden death in the population: the Paris Prospective Study I. Circulation 99: 1978-1983

14. Balkau B, Jouven X, Ducimetiere P, Eschwege E (1999) Diabetes as a risk factor for sudden death. Lancet 354: 1968-1969

15. Perry RC, Shankar RR, Fineberg N, McGill J, Baron AD (2001) HbA1c measurement improves the detection of Type 2 diabetes in high-risk individuals with nondiagnostic levels of fasting plasma glucose. Diabetes Care 24: 465-471 